\title{
Adolescent Sexual Behavior in an Urban Area of a Resource-Limited African Country, Cameroon
}

\author{
Félix Essiben ${ }^{*}$, Chantal Didjo², Valère Mve Koh³, Meka Esther Juliette Ngo Um4, \\ Christiane Nsahlai ${ }^{5}$, Pascal Foumane ${ }^{4}$
}

\author{
${ }^{1}$ Yaoundé Central Hospital, Department of Gynecology and Obstetrics, Faculty of Medicine and Biomedical Sciences, University \\ of Yaoundé I, Yaoundé, Cameroon \\ ${ }^{2}$ Department of Gynecology and Obstetrics, Faculty of Medicine and Biomedical Sciences, University of Yaoundé I, Yaoundé, \\ Cameroon \\ ${ }^{3}$ Yaounde Teaching Hospital, Department of Gynecology and Obstetrics, Faculty of Medicine and Biomedical Sciences, University \\ of Yaoundé I, Yaoundé, Cameroon \\ ${ }^{4}$ Yaounde Gyneco-Obstetric and Pediatric Hospital, Department of Gynecology and Obstetrics, Faculty of Medicine and \\ Biomedical Sciences, University of Yaoundé I, Yaoundé, Cameroon \\ ${ }^{5}$ Essos Hospital Center, Yaoundé, Cameroon \\ Email: *essibenx@yahoo.com, chantaldidjo@yahoo.com,vmvekoh@yahoo.com, estherum@yahoo.fr, cnsahlai@yahoo.com, \\ pfoumane2004@yahoo.fr
}

How to cite this paper: Essiben, F., Didjo, C., Mve Koh, V., Ngo Um, M.E.J., Nsahlai, C. and Foumane, P. (2019) Adolescent Sexual Behavior in an Urban Area of a Resource-Limited African Country, Cameroon. Open Journal of Obstetrics and Gynecology, 9, 923-935. https://doi.org/10.4236/ojog.2019.96090

Received: May 6, 2019

Accepted: June 27, 2019

Published: June 30, 2019

Copyright () 2019 by author(s) and Scientific Research Publishing Inc. This work is licensed under the Creative Commons Attribution International License (CC BY 4.0).

http://creativecommons.org/licenses/by/4.0/ (c) (i) Open Access

\begin{abstract}
Introduction: The substantial changes that occur in adolescence may lead to sexual behaviors that adversely affect their health. We have described sexual patterns in adolescents in various neighborhoods of Yaounde in order to underscore the sexual challenges that they face. Methods: We carried out a cross-sectional descriptive study in District number V of Yaounde from August 1 st to 31 st 2018 . To characterize their sexual lives, we surveyed 1800 adolescents between 10 and 19 , and analyzed the data using SPSS version 25.0. Results: In our study, 1023 (56.8\%) adolescents were female, and 777 (43.2\%) were male. Most of the adolescents were between ages 18 and 19 years (25.4\%), unmarried (93.1\%), had a secondary level of education (81.9\%) and lived with their families (87.3\%). One-third of the adolescents (30.7\%) were sexually active and $41.1 \%$ had multiple sexual partners. The average age of coitarche was 15.1 years. Among the females, 17.1\% reported one prior pregnancy and $30.8 \%$ had one abortion. Most of the sexual encounters were heterosexual (82.6\%) and $30.2 \%$ regularly used male condoms. $66.0 \%$ and $47.7 \%$ obtained information about sexuality primarily from social media and mass media, respectively. Conclusion: Sexual encounters in adolescents of District $\mathrm{V}$ of Yaounde were premature, mostly heterosexual and often unprotected. The consequences were an increased incidence of early pregnancies and abortions.
\end{abstract}




\section{Keywords}

Adolescents, Sexual Behavior, Heterosexual Relationship, Yaoundé, Cameroon

\section{Introduction}

Adolescence is characterized by the transition from childhood to adulthood, and the subjects undergo physical, psychological and emotional changes [1]. Sexual awareness that occurs during puberty results in adolescents being interested in sexual intercourse. Worldwide, about $47 \%$ of adolescents have already had sex. In the US, $6 \%$ of adolescents had their 1 st sexual encounter before age 13 years [2].

Adolescents are physically and emotionally immature. Their lack of experience in human and sexual relations rises their risk of being exposed to circumstances that have adverse consequences on their reproductive health and sexuality [3]. In 2011, 17.9\% of adolescents aged 15 - 24 years reported having had an STI [4]. Some consequences of STIs include infertility, ectopic pregnancies, and cervical cancer [5] [6] [7] [8].

Actually, adolescents are not only at risk of STI's and HIV infection, but also of unwanted pregnancies [9] [10]. These early pregnancies which often result in unsafe abortions are a major cause of morbidity and mortality in Africa [7] [11] [12]. A report from Cameroon in 2014 showed that $27.5 \%$ of women between ages 20 - 24 years had at least one live birth prior to being 18 years old [4].

Adolescent sexual behavior is influenced by several factors. Literature reports adolescent sexual decision making as a function of personal, familial and social factors [13] [14] [15] [16] [17]. Individual factors, such as age and gender, that will trigger the onset of sexual activity are not only governed by socio-cultural factors, but also by contextual factors, such as alcohol and drug use, and dropping out of school [15] [18]. According to Sturgeon et al., an intact family unit helps adolescents delay initiation of sex, have fewer sex partners, less STI's or premature pregnancies than their counterparts in broken families [19].

The onset of sexual activity varies according to series in the literature. The average age at first sexual intercourse was 14.86 years in 1996 South Africa versus 17.6 years in 2008 in France, respectively [20] [21]. According to the third Demographic and Health Survey the first sexual encounter in Cameroon in 2004 occurred at 16.5 years [22], whereas Foumane et al. reported 15.3 years in adolescent teenagers in urban areas of Cameroon in 2013 [23].

Cameroon is a low-income country in sub-Saharan Africa with about 22 million inhabitants. In 2012 adolescents constituted 23.2\% of the population [24]. Foumane et al. [23] reported that in $201321.3 \%$ of adolescents schooling in Yaounde were sexually active. MICS in 2014 reported that $16.0 \%$ of young women and 9.3\% of young men aged 15 - 24 years had sex before age 15 [25]. 
The development of effective services and policies addressing adolescent health issues should take into account the daily realities of adolescents. Meeting their needs is a challenge requiring being knowledgeable about their sexual and reproductive issues, their specific needs and problems resulting from their sexual behaviors. The goal of our study was to investigate adolescent sexual behavior and to seek determinants of their sexual activity in order to facilitate services rendered to them in a low-income country like Cameroon.

\section{Methods}

This was a cross-sectional descriptive study over a 5 months period, from May to September 2018, in the fifth district of Yaounde, located in the Mfoundi Division of the Center region. The area studied is about $20 \mathrm{~km}$ squared, of which $15 \mathrm{~km}$ squared is urban with an estimated population of 363118 inhabitants in 2014. This district is comprised of 11 neighborhoods, 7 in urban areas and 4 rural settlements. We included all adolescents age 10 - 19 years living in the study area and who accepted to participate in the study. Adolescents who did not have parental or guardian consent were excluded.

After approval of the authorities of the district of Yaoundé V, adolescents in our study area were invited to participate in the study. Adolescents were recruited during the vacation period at leisure spots and public places in the district. We performed simple stratified sampling.

We randomly chose 4 out of 7 neighborhoods in the urban areas and 2 out of 5 villages of the district. In each of these locales we identified adolescent leisure spots and places of gathering. Adolescents between age 15 and 19 years who voluntarily agreed to participate in the study were enrolled.

As a first step, fact sheets were given to participants to help them better understand the objectives of the study and ask questions. Adolescents less than 18 years received an additional consent form requesting parental approval. Secondly, after consent was received, the data sought were collected and recorded in a pre-established and pre-tested data collection form.

Participation in the study was entirely voluntary with free and informed consent of parents or guardians, and after completing the questionnaire, the participants placed them in envelopes which they sealed themselves to maintain confidentiality and anonymity.

We studied socio-demographic factors (age, ethnic origin, level of education, marital status of parents, location of home), factors pertaining to reproductive life (number of pregnancies, number of deliveries, number of spontaneous or induced abortions, number of living children), and sexual habits of boys and girls. The latter factor was further classified resulting in 7 variables to evaluate adolescent sexual behavior. These were sexual status (whether or not sexually active), age at first intercourse: premature (prior to age 16) or late ( $\geq 16$ years), multiple partners (more than 1 partner), frequency of sex (occasionally or once a month), type of sex (vaginal, anal, oral), sexual orientation (heterosexual, ho- 
mosexual or bisexual), use of male condoms during sexual intercourse (always or occasionally/never).

Early sexual intercourse, multiple partners and unprotected sex were considered high risk behaviors in our study.

The data obtained were registered and analyzed using Excel ${ }^{\circledR}$ and SPSS version 2.5. The data are expressed in numbers and frequencies for the qualitative variables, and in means with respective standard deviations for the quantitative variables. Pearson's Chi square test was used to compare qualitative variables, and the Fisher test to analyze variance. Spearman's test was used for correlation of quantitative variables, and Pearson for qualitative variables. Significance levels were set at $5 \%$.

\section{Results}

We contacted 2200 adolescents, of which 230 did not participate in the study for personal reasons, or parental prohibition. 1970 adolescents filled out the questionnaire but we excluded 170 surveys because they were filled improperly. Finally, a total of 1800 adolescents participated in the study, 1023 girls (56.8\%) and 777 boys (43.2\%).

\section{Socio-demographic characteristics}

Table 1 describes the adolescents' socio-demographic characteristics. The age range most represented of either gender was 18 - 19 years, 27.8\% girls $(284 / 1800)$ and $25.4 \%$ boys (196/1800). Mean age of girls surveyed was 14.8 years $( \pm 3.08)$ versus 14.6 years $( \pm 3.03)$ for boys. The level of education most represented was secondary for both genders, for girls $(82.0 \% ; 839 / 1800)$ and for boys $(81.8 \%$; $636 / 1800$ ). Of the adolescents who participated in the study, none of the boys were married while $6.9 \%$ girls $(71 / 1800)$ were. Most of the adolescents surveyed were in secondary school.

Majority of the participants lived at home, $86.6 \%$ (673/1800) boys and $88.1 \%$ (901/1800) girls, while a minority lived alone, 104 (13.4\%) girls and $122(11.9 \%)$ boys. Data of adolescents who lived alone were similar to adolescents with more than a secondary education and those without formal education, 50 (5.0\%) girls and 40 (5.2\%) boys. A significant number of adolescents lived in a single parent home, $15.1 \%$ (154/1023) for girls and 16.3\% (127/777) for boys. In divorced homes there were $17.1 \%$ girls $(175 / 1023)$ and $14.3 \%$ (111/777) boys, and those living with a widow(er) were $7.5 \%$ (77/1023) girls and 6.3\% (49/777) boys; 49/1800). Majority of the adolescents had at least one parent who had received a formal education, $83.2 \%$ (851/1023) for girls and $82.1 \%$ (638/777) for boys.

\section{Characteristics of reproductive life}

Table 2 describes the distribution of adolescents as a function coitarche and gender. The first sexual intercourse occurred at age 8 in boys and 9 in girls. The mean age at first sex was $15.1 \pm 2.2$ years, specifically $15.11 \pm 2.4$ for girls and $15.06 \pm 2.2$ for boys. We observed that $54.03 \%$ of boys had their first sexual encounter prior to age 16 years, and $58.48 \%$ of girls. Early intercourse occurred at similar ages in both sexes $(\mathrm{p}=0.324)$. 
Table 1. Socio-demographic characteristics.

\begin{tabular}{|c|c|c|c|}
\hline Variables & Girls n (\%) & Boys n (\%) & Total \\
\hline \multicolumn{4}{|c|}{ Age } \\
\hline Mean age (years) & $14.8( \pm 3.08)$ & $14.6( \pm 3.03)$ & \\
\hline \multicolumn{4}{|c|}{ Marital status } \\
\hline Unmarried & $952(93.1)$ & $777(100)$ & 1729 \\
\hline Married & $71(6.9)$ & $0(0.0)$ & 71 \\
\hline \multicolumn{4}{|c|}{ Educational level } \\
\hline Higher & $35(3.4)$ & $20(4.5)$ & 55 \\
\hline Secondary & $839(82.0)$ & $636(81.8)$ & 1475 \\
\hline Primary & $97(9.6)$ & $81(10.5)$ & 178 \\
\hline No formal & $52(5.0)$ & $40(5.2)$ & 92 \\
\hline \multicolumn{4}{|c|}{ Living situation } \\
\hline Alone & $122(11.9)$ & $104(13.4)$ & 226 \\
\hline With family & $901(88.1)$ & $673(86.6)$ & 1574 \\
\hline \multicolumn{4}{|c|}{ Parents' marital status } \\
\hline Unmarried & $154(15.1)$ & $127(16.3)$ & 281 \\
\hline Married & $617(60.3)$ & $490(63.1)$ & 1107 \\
\hline Divorced & $175(17.1)$ & $111(14.3)$ & 286 \\
\hline Widow(er) & $77(7.5)$ & $49(6.3)$ & 126 \\
\hline \multicolumn{4}{|c|}{ Educational level of parents } \\
\hline No formal & $172(16.8)$ & $139(17.9)$ & 311 \\
\hline At least one parent with formal & $851(83.2)$ & $638(82.1)$ & 1489 \\
\hline
\end{tabular}

Table 2. Distribution of adolescents as a function coitarche and gender $\mathrm{N}=1800$.

\begin{tabular}{ccccccc}
\hline $\begin{array}{c}\text { Age } \\
\text { (years) }\end{array}$ & $\begin{array}{c}\text { Girls } \\
\mathbf{n}(\%)\end{array}$ & $\begin{array}{c}\text { Cumulative } \\
\text { percentage }\end{array}$ & $\begin{array}{c}\text { Boys } \\
\mathbf{n}(\%)\end{array}$ & $\begin{array}{c}\text { Cumulative } \\
\text { percentage }\end{array}$ & $\begin{array}{c}\text { Both sexes } \\
\mathbf{n}(\%)\end{array}$ & $\begin{array}{c}\text { Total cumulative } \\
\text { percentage (\%) }\end{array}$ \\
\hline $8-9$ & $0(0.0)$ & 0 & $3(1.4)$ & 1.4 & $3(0.5)$ & 0.5 \\
$9-10$ & $4(1.2)$ & 1.2 & $3(1.4)$ & 2.8 & $7(1.3)$ & 1.8 \\
$10-11$ & $1(0.3)$ & 1.5 & $3(1.4)$ & 4.2 & $4(0.7)$ & 2.5 \\
$11-12$ & $15(4.4)$ & 5.9 & $8(3.8)$ & 8.0 & $23(4.2)$ & 6.7 \\
$12-13$ & $25(7.4)$ & 13.3 & $9(4.3)$ & 12.3 & $34(6.2)$ & 12.9 \\
$13-14$ & $35(10.4)$ & 23.7 & $19(9.1)$ & 21.4 & $54(9.9)$ & 22.8 \\
$14-15$ & $46(13.6)$ & 37.3 & $27(13.0)$ & 34.4 & $73(13.4)$ & 36.2 \\
$15-16$ & $71(21.0)$ & 58.3 & $38(18.3)$ & 52.7 & $109(20.0)$ & 56.2 \\
$16-17$ & $47(13.9)$ & 72.2 & $38(18.3)$ & 71.0 & $85(15.6)$ & 71.8 \\
$17-18$ & $43(12.7)$ & 84.9 & $32(15.4)$ & 86.4 & $75(13.7)$ & 85.5 \\
$18-19$ & $32(9.5)$ & 94.4 & $13(6.3)$ & 92.7 & $45(8.2)$ & 93.7 \\
$19-20$ & $19(5.6)$ & 100.0 & $15(7.2)$ & 99.9 & $34(6.2)$ & 99.9 \\
Total & $338(100.0)$ & & $208(99.9)$ & & $546(99.9)$ & \\
\hline
\end{tabular}


Table 3 describes the characteristics of adolescents' reproductive lives. Approximately $1 / 3$ of adolescents surveyed already had one sexual intercourse $(30.3 \%$; $546 / 1800), 26.8 \%(208 / 777)$ of the boys and $33.0 \%(338 / 1023)$ of the girls. The percentage of sexually active girls and boys was similar $(\mathrm{p}=0.168)$.

$17.1 \%$ (175/1023) of adolescents had been pregnant once. Approximately $1 / 3$ of pregnancies led to a termination that was voluntary in $67.3 \%(37 / 55)$ of cases. (Figure 1). Few adolescents sought health programs for concerns with their sexuality, for girls $(7.4 \% ; 76 / 1023)$ and boys $4.9 \%$; 38/1800).

\section{Adolescent sexual habits}

Table 4 describes adolescent sexual habits. 40.3\% (223/553) of sexually active adolescents had multiple partners with as many as 8 reported. Although this behavior was more frequently reported in boys than in girls, 43.0\%; 95/221 and $37.4 \% ; 128 / 342$, respectively, they were statistically comparable. More than $50 \%$ of sexually active adolescents surveyed had at least one sexual intercourse monthly $(57.8 \% ; 320 / 553)$. This occurred more often in boys $(59.7 \% ; 126 / 211)$ than in girls $(55.9 \%$; 194/342). Sexual orientation was predominantly heterosexual $(83.6 \%$; $462 / 553)$, with practically equal proportions in boys and girls, $(82.0 \% ; 173 / 211)$ and $(84.5 \% ; 289 / 342)$, respectively. Vaginal penetration was the most common type of sex $(66 \% ; 365 / 553)$ but it often occurred alongside oral sex, in boys $(26.2 \% ; 145 / 553)$ and girls $(23.4 \% ; 80 / 342)$. Only $1 / 3$ sexually active adolescent consistently used condoms $(31.2 \% ; 167 / 553)$ and it was more often male condoms $(\mathrm{OR}=1.56 ; \mathrm{p}<0.001)$.

Table 5 shows the influence of age on sexual habits. Sexual intercourse was often occasional in adolescents less than 15 years $(\mathrm{OR}=2.36 ; \mathrm{p}=0.013)$ and occurred less than once a month, as opposed the frequency in adolescents over 15

Table 3. Reproductive life characteristics.

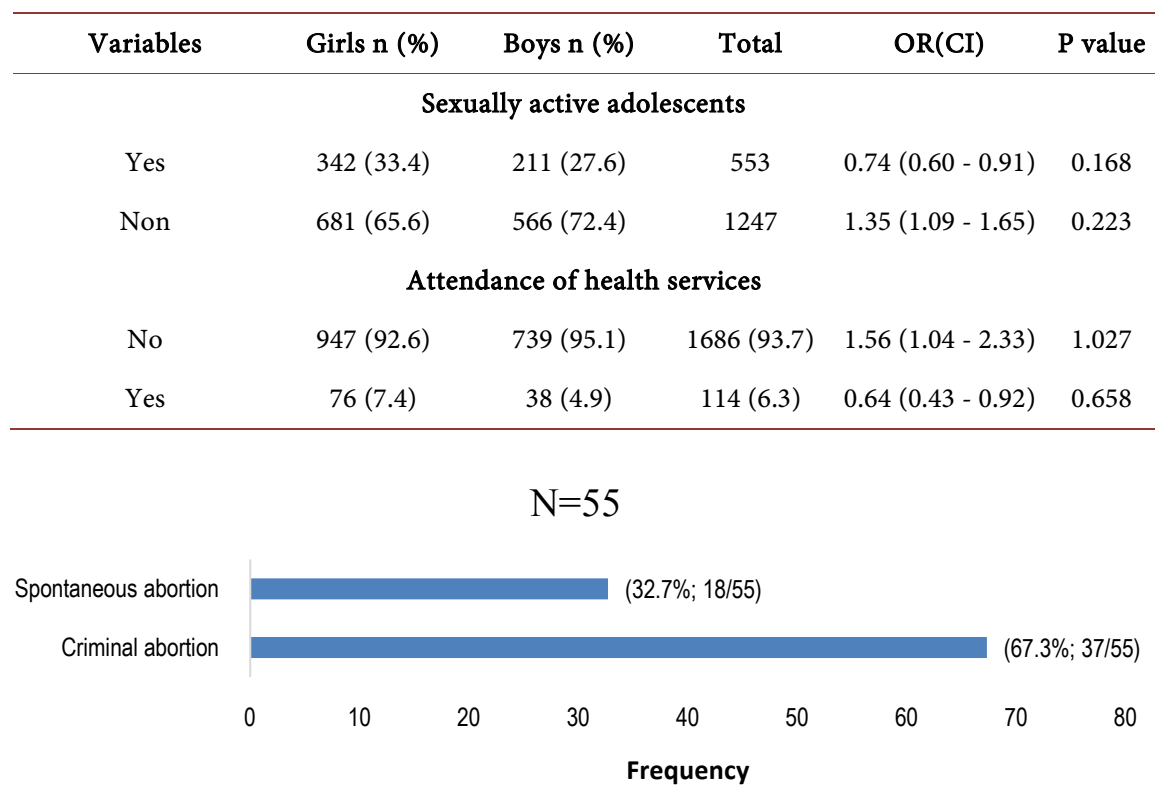

Figure 1. Distribution of adolescents as a function of type of abortion. 
Table 4. Adolescent sexual habits.

\begin{tabular}{|c|c|c|c|c|c|}
\hline Variables & $\begin{array}{l}\text { Girls } \\
\text { n (\%) }\end{array}$ & $\begin{array}{l}\text { Boys } \\
\text { n (\%) }\end{array}$ & Total & OR (CI) & $P$ value \\
\hline \multicolumn{6}{|c|}{ Number of sexual partners } \\
\hline 1 & $214(62.6)$ & $116(55.0)$ & $330(57.8)$ & $1.39(0.96-1.94)$ & 0.10 \\
\hline$\geq 2$ & $128(37.4)$ & $95(45.0)$ & $223(42.2)$ & & \\
\hline \multicolumn{6}{|c|}{ Frequency of sex } \\
\hline Occasional & $148(44.1)$ & $85(40.3)$ & 233 & $0.88(0.62-1.25)$ & 0.177 \\
\hline At least once monthly & $194(55.9)$ & $126(59.7)$ & 320 & $1.13(0.15-0.79)$ & 0.334 \\
\hline \multicolumn{6}{|c|}{ Sexual orientation } \\
\hline Heterosexual & $289(84.5)$ & $173(82.0)$ & $35(6.3)$ & $1.57(0.79-3.13)$ & 0.787 \\
\hline Homosexual & $18(5.3)$ & $17(8.1)$ & $462(83.6)$ & $0.83(0.52-1.31)$ & 0.970 \\
\hline Bisexual & $35(10.2)$ & $21(10.0)$ & $56(10.1)$ & $0.96(0.54-1.71)$ & 0.973 \\
\hline \multicolumn{6}{|c|}{ Type of sex } \\
\hline Vaginal & $241(70.5)$ & $124(58.8)$ & $365(66.0)$ & $0.59(0.41-0.85)$ & 0.834 \\
\hline Anal & $8(2.3)$ & $6(2.8)$ & $14(2.5)$ & $1.22(0.41-3.57)$ & 1.216 \\
\hline Vaginal and anal & $13(3.8)$ & $16(7.6)$ & $29(5.2)$ & $2.07(0.97-4.40)$ & 1.995 \\
\hline Vaginal and oral & $80(23.4)$ & $65(30.8)$ & $145(26.2)$ & $1.45(0.92-2.14)$ & 1.317 \\
\hline Anal and oral & $0(0.0)$ & $0(0.0)$ & $0(0.0)$ & -- & - \\
\hline \multicolumn{6}{|c|}{ Use of condoms } \\
\hline Always & $95(27.8)$ & $72(34.1)$ & 167 & $1.56(1.04-2.33)$ & $<0.001$ \\
\hline Sometimes or never & $247(72.2)$ & $139(65.9)$ & 386 & $0.64(0.42-0.95)$ & $<0.001$ \\
\hline
\end{tabular}

Table 5. Influence of age on adolescent sexual habits.

\begin{tabular}{|c|c|c|c|c|}
\hline Frequency of sex & $\begin{array}{c}\leq 15 \text { years } \\
\mathrm{N}=99 \\
\mathrm{n}(\%)\end{array}$ & $\begin{array}{c}>15 \text { years } \\
\mathrm{N}=454 \\
\mathrm{n}(\%)\end{array}$ & OR (CI) & $P$ value \\
\hline Occasionally & $60(60.6)$ & $179(44.1)$ & $2.36(1.51-3.68)$ & 0.013 \\
\hline Sex at least once a month & $39(39.4)$ & $275(55.9)$ & $0.16(0.09-0.26)$ & 0.014 \\
\hline Less than 2 sex partners & $99(100.0)$ & $422(93.0)$ & $15.35(0.92-252.13)$ & 0.009 \\
\hline More than 2 sex partners & $0(0.0)$ & $32(5.8)$ & $0.06(0.01-1.07)$ & 0.006 \\
\hline
\end{tabular}

$(\mathrm{OR}=0.16 ; \mathrm{p}=0.014)$. Whereas multiple partners were a feature seen in adolescents over 15 years $(O R=0.06 ; p=0.006)$ none of those less than 15 reported more than one sexual partner.

Table 6 shows adolescents' source of information on sexuality. A significant number of adolescents $(37.2 \% ; 670 / 1800)$ were unable to identify their source of information on sexuality. Only $9.5 \%$ (168/1800) received information from school and $2.3 \%(41 / 1800)$ from health care workers. Social media was the main source of information for adolescents, however, girls communicated more with their parents and seniors than boys $(\mathrm{p}=0.001)$ Table 6. 
Table 6. Distribution of sources of information on adolescent sexuality.

\begin{tabular}{cccccc}
\hline $\begin{array}{c}\text { Sources of information } \\
\text { on sexuality }\end{array}$ & $\begin{array}{c}\text { Boys } \\
\mathbf{N}=\mathbf{7 7 7} \\
\mathbf{n}(\%)\end{array}$ & $\begin{array}{c}\text { Girls } \\
\mathbf{N}=1023 \\
\mathbf{n}(\%)\end{array}$ & $\begin{array}{c}\text { Total } \\
\mathbf{N = 1 8 0 0} \\
\mathbf{n}(\%)\end{array}$ & OR (CI) & P value \\
\hline None & $327(42.1)$ & $343(33.5)$ & $670(37.2)$ & $1.44(1.19-1.75)$ & 1.255 \\
Friends & $30(3.9)$ & $41(4.0)$ & $71(3.9)$ & $0.96(0.59-1.55)$ & 0.963 \\
Parents/seniors & $\mathbf{3 0 ( 3 . 9 )}$ & $\mathbf{1 1 3 ( 1 1 . 0 )}$ & $\mathbf{1 4 3 ( 7 . 9 )}$ & $\mathbf{0 . 3 2 ( 0 . 2 1 - 0 . 4 9 )}$ & $\mathbf{0 . 0 0 1}$ \\
Medical personnel & $12(1.5)$ & $29(2.8)$ & $41(2.3)$ & $0.54(0.27-1.06)$ & 0.545 \\
Mass/social media & $218(28.1)$ & $318(31.1)$ & $536(29.8)$ & $0.86(0.70-1.06)$ & 0.903 \\
School & $90(11.6)$ & $78(7.6)$ & $168(9.3)$ & $1.59(1.15-2.18)$ & 1.519 \\
Multiple sources & $70(9.0)$ & $101(9.9)$ & $171(9.5)$ & $0.90(0.66-1.25)$ & 0.912 \\
\hline
\end{tabular}

\section{Discussion}

The reproductive health needs of adolescents require special attention because their psychological and social vulnerability may expose them to high-risk sexual behaviors. These risky behaviors may be associated with decisive consequences in the future. This often leads parents and society to introduce coercive measures aimed at limiting adolescent exposure to vulnerable situations. There are scarcely any health programs available for adolescents in our milieu. In this community-based study, we offered a perspective on the sexual behavior of 1800 adolescents and illustrated some of the components of adolescent sexuality.

The average age of the adolescents in our study was similar for the sexes, 14.7 years for boys and 14.8 years for girls. The most represented age range for both sexes in the study was 18 to 19 years (26.7\%). These results are similar to those published in 2013 by Kobelembi et al. in the CAR [26], and Foumane et al. in Cameroon [21], which reported an average age of 14.7 years. The majority of our participants were in secondary school since we recruited in urban or peri-urban areas where the school enrollment rate of $87 \%$ [4].

There were $6.9 \%$ married girls versus no married boys. This figure is double that reported in 2013 by Foumane et al. that showed 2.5\% married girls in secondary school [23]. This discrepancy can be explained by the population sampled; whereas Foumane et al. surveyed only secondary school adolescents, our study for inclusive or all adolescents, irrespective of schooling. However, our percentages were less than the national average. In 2012 according to UNICEF $24.2 \%$ of adolescents in Cameroon were married or in cohabitation [24]. In Côte d'Ivoire, these figures are more alarming because $36 \%$ of women were already cohabiting before the age of 18 years [27]. Schooling limits the risk of early marriage, which explains the low proportion of married teenagers in our study.

In our study, $13.4 \%$ of boys and $11.9 \%$ of girls no longer lived at home. Living at home depends not only on the level of education but also on the living conditions. Adolescents living outside the home are often students who break free from parental control upon university admission. In our study adolescents not living at home were usually in a university $(\mathrm{p}<0.001)$. According to Rwenge $\mathrm{M}$, 
family composition and standards of living were the most common factors associated with high risk sexual behaviors [28].

$17.1 \%$ of our participants had been pregnant once with $61.1 \%$ pregnancy termination. These percentages are higher than those Foumane et al. reported in 2013 with $10.1 \%$ pregnancies, but a pregnancy termination rate similar to ours [23]. However, our pregnancy numbers are lower than those reported in Yaoundé in 2012 by the Central Bureau of Census and Central Population Studies of Cameroon. This agency reported an adolescent pregnancy rate of $24.0 \%$ and a pregnancy interruption rate of 33.3\% [29]. Early pregnancy among school girls will often lead to an abortion because they are mostly unwanted and unplanned. The higher rate of abortions in this more educated population can be explained by the fact that pregnancy could interfere with the adolescents' plans for school.

$30.5 \%$ of the adolescent had early sex, specifically $27.6 \%$ boys and $33.4 \%$ girls reported one sexual encounter. This finding is lower than that reported in Burkina Faso by Adohinzin et al. which showed 54\% [6]. The number of sexually active girls was comparable to that of boys $(\mathrm{p}=0.17)$. The mean age at first sex was 15.1 years in both genders. We noticed a significant number of girls who are sexually active before age 16 years. Many studies describe a progressively decreasing age at first sexual intercourse [4] [11] [30]. An explanation of early sex may be that young people grow up in a rapidly changing environment that continually offers new discoveries. Globalization, access to new communication techniques, rapid urbanization and changing social norms are all factors that arouse young people's curiosity and thus expose them to early sexual encounters. Like other authors [6], there was a positive correlation between school attendance and early sex because only $6.7 \%$ of adolescents beyond the secondary level of education were sexually active compared to $82.3 \%$ of those in secondary school. We can assume that the educational environment is a milieu that creates opportunities for young people to network and make good decisions pertaining to their sexuality. Educated youth are likely to have the knowledge and attitude necessary to resist peer pressure and take responsibility for their lives. Information on sexuality as well as essential skills should be integrated early in the schooling process such that adolescents reap the benefits thereof. As such, even young people who drop out of school be able to benefit from such early integration.

Multiple sexual partners were observed in adolescents at $41.2 \%$, albeit more in boys than girls but without statistical significance $(\mathrm{p}=0.26)$. Our percentages are higher than those reported by Yode et al. in 2012 in Burkina Faso [31], which showed that $11.5 \%$ of boys ages 15 to 24 years reported having had sex with at least two partners versus $0.9 \%$ of girls. Early sexual intercourse predisposes to multiple sexual partners [6]. This can be explained by the fact that adolescents reported mass and social media as their principal source of information on sexuality. Undoubtedly mass media has an effect on adolescents' sexual behavior by shaping, influencing, conveying values and new attitudes that are gradually refined and ultimately fine-tuned, thereby becoming a dominant component in 
shaping their sexuality given that the adolescent's personality is not yet totally set.

As mentioned above early sexual intercourse predisposes to multiple sexual partners. Early age at first sexual intercourse is associated with an increased risk of HIV infection because of multiple sexual partners and a longer period of sexual activity before establishing long-term monogamous relationships [6] [32].

Sex is often occasional at first and tends to be more regular with the establishment of faithful partners. In our study $40.3 \%$ boys and $44.1 \%$ girls reported having occasional sex. In 2013 Makenzius et al. [30] reported more frequent sex with increasing age. Most of the adolescents (66.0\%) confirmed having vaginal intercourse. The existence of other ways of penetration as well as homosexual relations highlights the exploratory nature of their sexual behavior.

Our adolescents used male condoms infrequently. The non-use of condoms is strongly associated with early sexual intercourse and the level of education of adolescents. A significant number of adolescents hardly or never use male condoms (70.8\%). We observed that $19.2 \%$ of adolescents less than 16 years used condoms, versus $29.7 \%$ more than 16 years. These results are comparable with those of Kobelembi et al. in CAR in 2013 [26]. Boys are more likely to use condoms during sex than girls $(\mathrm{p}<0.001)$, probably because the male condom is more popular and easier to use. The other reason could be the challenge girls face in insisting that their partners use condoms since sex if often occasional and unplanned.

\section{Study Limitations}

Our study had certain limitations. We did not research the prevalence of STIs-HIV in our study population, which would have given us a better perspective on the consequences of these risky behaviors and endorse our recommendations.

\section{Conclusion}

The high enrollment rate of adolescents in the Yaoundé V district should help to improve adolescents' sexual behavior because they have early sexual relations. Adolescents' high-risk behaviors may expose them to unwanted pregnancies and abortions. The low rate of condom use also exposes them to sexually transmitted infections. The factors associated with these high-risk behaviors, and the primary sources of information of these adolescents need to be considered in the development of youth sexuality education programs and these programs need to be implemented early in the community.

\section{Acknowledgements}

The authors thank the administrative personnel of the Yaoundé V council to have facilitating the implementation of this study.

\section{Authors' Contributions}

Félix Essiben, Pascal Foumane and Chantal Didjo conceived the study, partici- 
pated in the study design and collection of data. Ngo Um Meka Esther has been involved in analysis and interpretation of data and drafting the manuscript. Mve Koh Valère and Nsahlai Christiane reviewed of the article and Foumane Pascal reviewed and supervised the study. All authors have read and approved the final manuscript. Apart from the personal contribution of each author, the study was not funded.

\section{Conflicts of Interest}

The authors declare no potential conflicts of interest.

\section{References}

[1] World Health Organization, Commonwealth Medical Association Trust and UNICEF (2006) Maternal, Newborn, Child and Adolescent Health. Orientation Programme on Adolescent Health for Health-Care Providers. https://www.who.int/maternal_child_adolescent/documents/9241591269/en

[2] Maria, R.T.G. and Lyndsey, A.P. (2014) High-Risk Behaviors in Youth. University of Nebraska, Lincoln. http://extensionpublications.unl.edu/assets/pdf/g1715.pdf

[3] Wells, E. (2013) Addressing Adolescent Sexual and Reproductive Health in a Complex World. Outlook, 30, 1-8.

[4] DHS-MICS (2011) Demographic and Healthsurvey and Multiple Indicators Cluster Survey in Cameroon.

http://www.statistics-cameroon.org/downloads/EDS-MICS11/DHSMICS_2011_prel iminary_report.pdf

[5] Boislard-Pépin, M.-A. (2010) Sexual Precocity and Adolescent Sexual Behavior: A Longitudinal Study of Individual, Family Factors in the Group of Friends and Associated Context. Unpublished Doctoral Thesis, The Université du Québec à Montréal, Québec. https://archipel.uqam.ca/3101/1/D1892.pdf

[6] Adohinzin, C.C., Meda, N., Belem, A.M., Ouédraogo, G.A., Sombie, I., Berthe, A. and Fond-Harmant, L. (2016) Risk Assessment in Young People Living in Bobo Dioulasso: Analysis of Factors Associated with Sexual Precocity and Multiple Partners. Pan African Medical Journal, 25, 132. https://doi.org/10.11604/pamj.2016.25.132.9767

[7] De Muylder, X. (2004) The Sexual Health of Adolescent Girl. Louvain Medical, 123, 52-59.

[8] Hamada, H., Zaki, A., Nejjar, H., Filali, A., Chraibi, C., Bezad, R. and Alaoui, M.T. (2004) Pregnancy and Delivery in Adolescents: Characteristics and Profile of 311 Cases. Journal de Gynécologie Obstétrique et Biologie de la Reproduction, 33 607-614. (In French) https://doi.org/10.1016/S0368-2315(04)96601-X

[9] World Health Organization (2018) Adolescent Pregnancy. https://www.who.int/news-room/fact-sheets/detail/adolescent-pregnancy

[10] Yakam, J.C.T. (2009) Adolescent Reproductive Health in Africa: A Global Approach. Natures Sciences Sociétés, 1, 18-28. (In French) https://doi.org/10.1051/nss/2009004

[11] Guiella, G. (2012) Adolescent Sexual Behavior in Sub-Saharan Africa: The Example of Burkina Faso, Ghana, Malawi and Uganda. Doctoral Thesis, The Université de Québecà Montréal, Québecà.

https://papyrus.bib.umontreal.ca/xmlui/handle/1866/6926 
[12] Essiben, F., Nana, P.N., Damtheou, S., Moukouri, S.G.F., Ojong, S.A., Ngate, A., Eko, E.F. and Mbu, R.E. (2017) Adolescent Pregnancies: Maternal and Fetal Complications in Yaounde University Hospitals. Journal Gynecology and Reproductive Medicine, 1, 1-5. https://doi.org/10.33140/JGRM/01/02/00003

[13] Pilgrim, N.A. and Blum, R.W. (2012) Protective and Risk Factors Associated with Adolescent Sexual and Reproductive Health in the English-Speaking Caribbean: A Literature Review. Journal of Adolescent Health, 50, 5-23. https://doi.org/10.1016/j.jadohealth.2011.03.004

[14] Akers, A.Y., Gold, M.A., Bost, J.E., Adimora, A.A., Orr, D.P. and Fortenberry, J.D. (2011) Variation in Sexual Behaviors in a Cohort of Adolescent Females: The Role of Personal, Perceived Peer, and Perceived Family Attitudes. Journal of Adolescent Health, 48, 87-93. https://doi.org/10.1016/j.jadohealth.2010.05.004

[15] Madkour, A.S., Farhat, T., Halpern, C.T., Godeau, E. and Gabhainn, S.N. (2010) Early Adolescent Sexual Initiation as a Problem Behavior: A Comparative Study of Five Nations. Journal of Adolescent Health, 47, 389-398. https://doi.org/10.1016/j.jadohealth.2010.02.008

[16] Cubbin, C., Brindis, C.D., Jain, S., Santelli, J. and Braveman, P. (2010) Neighborhood Poverty, Aspirations and Expectations, and Initiation of Sex. Journal of Adolescent Health, 47, 399-406. https://doi.org/10.1016/j.jadohealth.2010.02.010

[17] Haydon, A.A., Herring, A.H., Prinstein, M.J. and Halpern, C.T. (2012) Beyond Age at First Sex: Patterns of Emerging Sexual Behavior in Adolescence and Young Adulthood. Journal of Adolescent Health, 50, 456-463. https://doi.org/10.1016/j.jadohealth.2011.09.006

[18] Ronis, S.T. and O’Sullivan, L.F. (2011) A Longitudinal Analysis of Predictors of Male and Female Adolescents' Transitions to Intimate Sexual Behavior. Journal of Adolescent Health, 49, 321-323. https://doi.org/10.1016/j.jadohealth.2010.12.010

[19] Sturgeon, S.W. (2008) The Relationship between Family Structure and Adolescent Sexual Activity. The Heritage Foundation, Washington DC.

[20] Bajos, N. and Bozon, M. (2008) Survey on Sexuality in France: Practice, Gender and Health. La Decouverte, Paris, 117-147. (In French)

[21] Buga, G.A., Amoko, D.H. and Ncayiyana, D.J. (1996) Sexual Behaviour, Contraceptive Practice and Reproductive Health among School Adolescents in Rural Transkei. South African Medical Journal, 86, 523-527.

[22] Cameroon's National Institute of Statistics [Internet] Cameroon: National Institute of Statistics of Cameroon (2004) Third Demographic and Health Survey. http://www.statistics-cameroon.org/

[23] Foumane, P., Chiabi, A. and Kamdem, C. (2013) Sexual Activity of Adolescent School Girls in an Urban Secondary School in Cameroon. Journal of Reproduction and Infertility, 14, 85-89.

[24] UNICEF (2012) Statistics/Cameroon. https://www.unicef.org/french/infobycountry/cameroon_statistics.html

[25] Cameroon's National Institute of Statistics (2014) Cameroon 2014 MICS Key Findings Report. Final Report.

http://slmp-550-104.slc.westdc.net/ stat54/downloads/2016/MICS5_CMR2014_RA PPORT_FINAL.pdf

[26] Kobelembi, F. (2005) The Sexual Behavior of Adolescents in Bangui (CAR). African Population Studies, 20, 2. (In French)

http://aps.journals.ac.za/pub/article/view/396/354 
[27] Demographic and Health Survey and Multiple Indicators (2012) ICF International Calverton, Maryland, USA June 2013. National Institute of Ivory Coast Statistics. (In French) https://www.dhsprogram.com/pubs/pdf/FR272/FR272.pdf

[28] Mburano, R. (2000) Sexual Risk Behavior among Youths in Bamenda, Cameroon. International Perspectives on Sexual and Reproductive Health, 26, 13-18. (In French) https://doi.org/10.2307/2648300

[29] Central Bureau of Censuses and Population Studies (2015) Report of the Survey of Opinions and Knowledge of Adolescents on Sexual Health in Schools in the City of Yaoundé. BUCREP/EESSAMS, 20-45. (In French)

[30] Makenzius, M. and Larsson, M. (2013) Earlyonset of Sexual Intercourse Is an Indicator for Hazardous Lifestyle and Problematic Life Situation. Scandinavian Journal of Caring Sciences, 27, 20-26. https://doi.org/10.1111/j.1471-6712.2012.00989.x

[31] Yode, M.L. and Le Grand, T. (2012) Association between Age at First Sexual Relation and Some Indicators of Sexual Behavior among Adolescents. African Journal of Reproductive Health, 16, 173-188.

[32] Akwara, P., Madise, N. and Hinde, A. (2003) Perception of Risk of HIV/AIDS and Sexual Behaviour in Kenya. Journal of Biosocial Sciences, 35, 385-411.

https://doi.org/10.1017/S0021932003003857 